ISBN 978-93-84422-79-0

6th International Conference on Humanities, Interdisciplinary Studies, Hospitality and Tourism

Management (HISHTM-17)

Singapore Aug. 10-11, 2017

\title{
To Explore the Green Management, Raising Processes and Marketing Channels of Aquaculture: A Case Study of Barramundi in Tainan, Taiwan
}

\author{
Shu-Fang Hsu \\ Graduate School of Business and Operations Management, Chang Jung Christian University, \\ Taiwan, R.O.C. (e-mail:h99582004@gmail.com) \\ Department of Food and Beverage Management, Far East University, No.49, Zhonghua Rd., Xinshi Dist., \\ Tainan City 74448, Taiwan (R.O.C.)
}

\begin{abstract}
In response to consumer awareness of aquatic quality and market demand, fishery cultivation skill has been continued to progress in recent years in Taiwan. So that consumers have a good aquatic quality is the purpose of aquaculture. In this study, an ecological farmer, Mr. Dingxin Wang (hereinafter referred to as "Mr. Wang" ), in Tainan, Taiwan, as a case. Mr. Wang is used to take both of "wholesale purchase" and "self-market sale" as his sale channel. First, to be purchased by the wholesaler followed by Mr. Wang to bring the remaining fish shipped to the market or home delivery. In this study, using observation and interview method to explore the environmental management, aquaculture process and marketing channel of ecological aquaculture for barramundi. Environmental management will affect the marketing model such as fishery oxygen content, health management, etc. which will affect the fish meat, the smell of fish and other quality. Therefore, the raising food and medication details etc. are very important in the raising process. The study showed that good quality of fish meat decided the market sell or home delivery. Sales may be increased through network and open up the different marketing channels and it will be an inevitable trend in the future. The producer knew the concept of customer-oriented green consumption to create a new value of the product, that is, the entrepreneurial value of the producer.
\end{abstract}

Keywords: Barramundi, Marketing Channel, Ecological Aquaculture, Aquaculture Producer

\section{Introduction}

The pursuit of healthy and nutritious diet concept has become a hot topic in recent years. The growth of fish farming technology, usually are required by the high temperature, for subtropical Taiwan is very mature, such as barramundi which with short raising time and the high rate of meat, are more popular by aquaculture producer. The price of barramundi is inexpensive, and its quality is poor. Although it can grow fast under the low salinity, the meat is relatively loose. This has a considerable impact on the barramundi aquaculture industry in Taiwan. Moreover, some professional on barramundi aquaculture industries are not seeking sophisticated.

The fact was that the aquaculture producer sold a large number of barramundi to the wholesaler with low prices to increase their profits as long as the fish as less bitter and algae taste. However, the consumers began to love the high quality value fish followed by the economic take-off and the increased income. This is similar to the concept of green production. According to definition of the United Nations Environmental Program, UNEP, the so-called green products, also known as cleaner production, are strategies that continually apply integration and prevent environmental pollution in processes, products and services to increase ecological benefits and reduce human and environmental hazards" which be used in food production is known as green products food [1]. [2] pointed out that green production refers to the strategy of continuous application integration and prevention of environmental pollution, in the process, products and services, to increase the ecological benefits and reduce the harm to humans and the environment. Mr. Dingxin Wang (hereinafter referred to as Mr. Wang), 
an aquaculture producer in this case study, has begun his aquaculture in 2003. His father was also an aquaculture worker, so Mr. Wang contacted with aquaculture when he was in childhood. Due to his siblings had no ambition to take aquaculture industry, Mr. Wang decided to return home to take over it and transformed his way from professional aquaculture to ecological aquaculture because he was lack of huge capital. Mr. Wang committed to raise the barramundi with fleshy and without the algae smell. He has continually adjusted both in raising and environmental management and he did not care about the time cost due to the barramundi could not be raised throughout the whole year. Mr. Wang also sold his fish to the traditional market and developed the home delivery channel by himself in addition to the wholesale purchase. The process of his efforts and results are the motivations of this study. The purpose of this study is that to explore the producer concerning of green management.

\section{Literature Review}

The major raising areas of barramundi in Taiwan's is under the south of Chiayi where the higher temperature could be suitable for the barramundi fish. The rapid growth and less sickness had made the barramundi amount to reach the peak in 1992 to 1995 . But the domestic market could not meet the excess production. The fish prices even had been fallen to the edge of the cost, making a lot of fishers lose money, because of imbalance in production and marketing, many barramundi producers had been withdrawn the market after 1998. Barramundi industry was in a bottom condition in 2000, export companies actively found a new way out for the industry. The barramundi aquaculture skill has been improved under the consumers demand in recent years. Nowadays, barramundi aquaculture has become a common raising species [3] . [4] pointed out that Taiwan's barramundi was still dominated by lateolabrax japonicas. The data showed that lateolabrax japonicas easily live whatever in tropical, subtropical, fresh water, brackish water and the whole sea water. However, barramundi is tropical species which is a wide salty fish and intolerant low temperature, only suitable for raising in southern Taiwan. Meanwhile, barramundi is unable to have the mass production throughout the year, so the yield was less than lateolabrax japonicas. [5] considered that aquaculture producers usually grew their own fish from fries, then, to be purchased by the wholesale or processing plant after meeting the market specifications. As for domestic consumer market, it usually access via the auction of fishing market or logistic channel from wholesaler. While, export products are exported after processing. He pointed out that it was different between domestic consumer market and export markets according to fish size. It can be divided into four types of aquaculture, and also there are the different distributors: (1) To supply the domestic market demand, raising time of about 5 to 7 months, smaller size, higher price than export about 10-20 percent ; (2) more than $1 \mathrm{~kg}$, raising time of more than nine months, larger size than domestic market, large acquisitions, less price than domestic market ; (3) To enhance the aquaculture density in the early stage, nearly 6 months, first sale to domestic market, then, sale the remaining till raising to the export size ; (4) The raising time of more than 2 years, more than $4 \mathrm{~kg}$, the increasing in the purchase price, however, the capital investment was quite amazing, the relative risk of natural disasters also increased.

\section{Study Method}

The essence of case study is that it tries to clarify one or a group of decision: Why they will be adopted, how to implement, and what kind of results will be. The sources of these materials are combined with practice, from which the assumptions and theories are more feasible. [6]pointed out the immersion/ crystallization analysis style. Chang said that a researcher likes an explorer or a thinker, long-term study in the text in order to master, through continuous review of relevant experience into the overall analysis coupled with insight into the experience gained by the new insights, and the correlation between each other, and finally extract the report of the social reality of the paper. Its purpose was to dial through the real insider interview, the real meaning, the impact, future development and solution.

The Figure 1 study framework is as the main interviewer of aquaculture producer. This case study was to explore the aquaculture method and aquaculture environment management, and raised out of each $1 \mathrm{~kg}$ of barramundi fish. Be purchased by wholesaler was the major market channel for barramundi producer, and sale 
on the market by self and home delivery was the secondary access. Therefore, this study was divided into "before depth interview" and "formal depth interview". First, the researcher participated 4 times of barramundi management at the aquaculture field including the daily work and process before depth interviews.

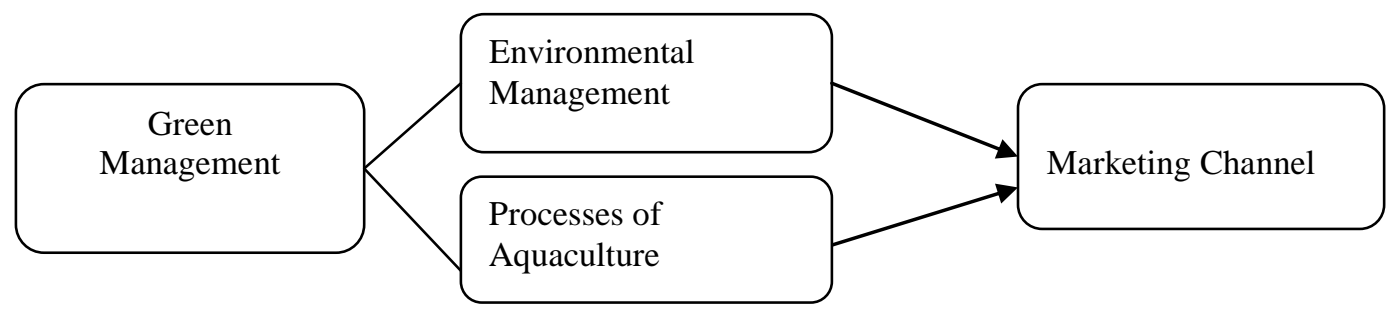

Fig 1 Study Framework

\section{Data Analysis}

\subsection{The Actual Aquaculture of Barramundi}

The most concerning for the wholesaler about the fish is if there is soil smell or not, they do not care about whether the fish is in good condition or not. In general, with the soil smell is higher under freshwater. Actually, it is not the same fish feed comparing to raise with 40,000 fish and with 10,000 fish under the same raising area and water. It needs 120 bags of fish feed for $6,000 \mathrm{~kg}$ fish and $500 \mathrm{bags}$ of fish feed for $24,000 \mathrm{~kg}$ fish. More fish feed causes more fish feces. Then, the more fish feces make the higher oxidation under the same aquaculture area and water, which is the major reason for the smell of soil. The aquaculture producer will inform the wholesaler when fish is raised to meet the required weight. Later, the wholesaler will confirm the size of fish, and bring one fish away to taste if there is soil smell or not, the relevant work flows will be arranged, including the exact date and time to collect the fish, after making sure the fish quality. Finally, the wholesaler will select the workers to collect the fish, and the wages are usually paid by the aquaculture producer. The remaining fish will be sold to traditional market or home delivery by the producer. The weekly sales are about 50 to 80 fish. In addition, it could be sold more than 200 fish monthly by home delivery service through the introduction by friends or relatives. The producer can only earn NT $\$ 10$ for each fish from raising to sell, however, the wholesaler can have NT $\$ 40$ profits for each fish and he is just for resale.

Mr. Wang:

"The cost for raising each fish is NT\$50, and sell to the wholesaler may be only NT\$55 to 60, but the wholesaler may sell up to NT\$100 to consumers for each fish. I work very hard and only NT\$10 profits, but the wholesaler just resale and NT\$40 profit for per fish. This is what I think is unreasonable, if so, as I sell by myself. I do my business slowly if I have the ability to handle."

According to the contract, all the fish in the pool is owned by the wholesaler. First, the wholesaler takes away $5,400 \mathrm{~kg}$ on the base of $6,000 \mathrm{~kg}$ in a fish pool, the wholesaler then takes the remaining $600 \mathrm{~kg}$ fish away after the pool water was totally released. If there is no contract, the producer will take the remaining 500kg fish to sell on the market by producer after being taken away 4,800kg from a fish pool. The aquaculture producer handles by himself in both raising and sales. In order to promote the access, the producer deals with home delivery orders from Monday to Thursday and sells his fish on the market on weekend or holiday. The aquaculture producer wants to develop the network market access, but he is not good at online community operation and shopping for his own aquatic products. A total of 6 hectares of aquaculture field, a total of 12 pools for 0.5 hectares each pool, annual rent of NT\$150,000-. The basic equipments consist of electric boxes, cables, windmills, pumps, automatic feeding machine. The overall cost was more than NT\$1million. The breeding fishes contents gentian grouper, grouper, bass and milkfish as well. One of the pools is the mixed one of gentian grouper, grouper and bass. Grouper and bass are with small fish or shrimp as for their food. The similar size will not eat or attack each 
other, so they could be raised together. It prefers the whole barramundi in Taiwan cuisine. Usually, the regular size of barramundi, about $1 \mathrm{~kg}$, is dominated by domestic sales selling restaurants, traditional markets or supermarkets. "No selling, no money", the producer can decide what kind of fish to raise, and how size to be raised to sell after the market access is cleared.

\subsection{Aquaculture Environmental Management of Barramundi}

The fish price will be determined by the fish breeding rate. Some other factories such as typhoons, sudden drop in temperature and other natural disasters will cause a big damage even lose money. As for distributors, there are two kinds of wholesaler for selling $0.6 \mathrm{~kg}$ and $1.8 \mathrm{~kg}$. Aquaculture environment is very important for fish's growing up. First, to cleanup fish pond, then start to raise the fish after dry and clean water quality. It should be ruled out the hidden algae inside the fish pond, and sterilization through the sunburn is also necessary, otherwise the algae will affect the difficulty of purification of water quality. Fish can start to raise after the pond is cleaned Usually, and water purification is good. Usually, a windmill can take care of the amount of oxygen required for $1,500 \mathrm{~kg}$ fish. The numbers of windmills for each fish pond will be determined by the fish amount. In general, it is about 10,000 barramundi fish in a pool. And the fries will release into the fish pond during spring and summer and can be harvested in autumn, because the barramundi will not grow up in winter. The feeding time for barramundi is three hours before the dawn and three hours before the dusk, and the using of automatic feeding machine can reduce the manpower. Producer owns a total of 12 ponds, feeding fish at least one hour every day, and patron the fish pond once in the morning and in the evening respectively. A pool contents of about 10,000 fish, the normal one is 40,000 fish in a pool, but the breeding work will not be reduce due to the less fish. Moreover, because the salty fish pool is not suitable to raise the density fish amount. The saltier water will be less oxygen content. The insufficient oxygen content will cause the soft meat of barramundi. June and July are the proper time to feed barramundi. The weather is hotter, the easier to feed fish and vice versa. The socalled "Feed Conversion Rate, FCR" refers to the food transferred into muscle. FCR for barramundi is about 0.7 to $0.8 \mathrm{~kg}$ of feed into $0.6 \mathrm{~kg}$ of flesh, so the FCR is about $80 \%$.

Mr. Wang:

"30 kg fish feed for NT\$1500 equals to $1 \mathrm{~kg}$ fish feed for NT\$50. So raise 0.6kg barramundi will cost NT\$40 $(N T \$ 50 \times 0.8 F C R=N T \$ 40)$. A fry is NT\$5, add the electricity pay and wages, so the cost of a barramundi is at least NT\$50. This is the lowest cost, add the medication, or breeding rate is not good, the cost will be higher."

Because the wholesaler won't collect the overweight fish, the fish continue to raise if more than $0.6 \mathrm{~kg}$. The producer needs to find another wholesaler if the fish is over $1.8 \mathrm{~kg}$. The overweight fish will be cut into fillet and export. The export fish usually has to raise more than $1.8 \mathrm{~kg}$, because a fish is usually cut into 2 fleshy boneless pieces of meat. The other reason is the removed head, bones and internal organs almost weight $0.6 \mathrm{~kg}$, so it is necessary to have more than $1.6 \mathrm{~kg}$ for export process. The quality of aquaculture products will be judged by the consumers. The longer raising time, the increasing risk and cost will be followed. The aquaculture producer does not care about the raising time, because he is very confident to his own aquatic products.

The aquaculture producer handles by himself in both raising and sales. In order to promote the access, the producer deals with home delivery orders from Monday to Thursday and sells his fish on the market on weekend or holiday. The aquaculture producer wants to develop the network market access, but he is not good at online community operation and shopping for his own aquatic products. Fish meat depends on the breeding density. High density creates the less space for fish and vice versa. The fish meat is more delicious under the enough space. The aquaculture field must install the basic equipment such as windmill in addition to the upgrading of aquaculture techniques and management. Further, the fish feed manufacturer often asks to cash transactions, because the fear of dead fish or debt, so the price of feed can't afford to offer any discount even buy a lot. Due to the consumers insist on the healthy and good taste of fish, to prepare the medicine for the sick fish or to avoid being infected to the whole pool of fish is necessary and this creates an extra expenditure for the producer. Infrastructure and feed require to pay by cash to form the financial pressure. Differences in Analysis. 


\section{Conclusion}

Ecological aquaculture is based on low-density aquaculture, a pool for 10,000 fish, unlike high-density aquaculture. The pressure source comes from its infrastructure and cash expenditure for feed fee. It has a great cost gap comparing with high-density aquaculture, but the quality is higher than the latter. Ecological aquaculture has made the barramundi taste extremely delicious. When the harvest, the wholesales buy the adult fish which makes the producer has a fixed income and the producer can also run their own retail market.

The study showed that the excellent fish quality raised by ecological aquaculture is better than traditional aquaculture. The producer is currently in contact with the network and home delivery business. Still, the producer does not fully understand the computer and network store operation, because only one person engaged in so complicated work. If there are young people who are willing to join the network to sell, the sales of barramundi business is bound to have a new growth in the future. The producer's business can bring benefits for him and more favorable ecological sustainable management. The producer actively establishes the mutual trust with customers in order to increase revenue performance. The producer's customer-oriented consumption creates the new value of the product, that is, the value of the producer. The studied showed that the constantly learning and applied the modern technology can solve the dilemma, green consumption can naturally become the mainstream of the future industry.

\section{References}

[1] United Nations Environmental Program, UNEP(2012). Retrieved from, http://www.unep.org/resourceefficiency/

[2] S. Akgüngör, B. Miran, and C. Abay, “Consumer Willingness to Pay for Organic food in urban turkey,” Journal of International Food \& Agribusiness Marketing, vol.22 (3-4), pp.299-313, June 2010.

[3] J. Y. Dai, “The bass is diving and the international go forward," Fisheries Extension, vol. 362, pp.18-19, December 2016.

[4] Agriculture Commission of the Executive Yuan (2015). Taiwan's barramundi was still dominated by lateolabrax japonicas. Retrieved from, http://www.fa.gov.tw/cht/Publications/index.aspx

[5] W. C.Lin, Z. T. Huang, and X. Liao, Study on the Optimum Scale of Bass Culture. 2011, Taiwan Fisheries Association, Abstract of Papers, Academic Papers Presentation. p53.

[6] F. F. Chang, “The Five Steps of Qualitative Data Analysis: Climbing up a Ladder of Abstraction,” Journal of Elementary Education, vol.35, pp.87-120, April 2010. 